\title{
Burn-out, circumferential film flow distribution and pressure drop for an eccentric annulus with heated rod
}

Andersen, P.S.; Jensen, A.; Mannov, G.; Olsen, A.

Publication date:

1973

Document Version

Publisher's PDF, also known as Version of record

Link back to DTU Orbit

Citation (APA):

Andersen, P. S., Jensen, A., Mannov, G., \& Olsen, A. (1973). Burn-out, circumferential film flow distribution and pressure drop for an eccentric annulus with heated rod. Risø National Laboratory. Risø-M No. 1623

\section{General rights}

Copyright and moral rights for the publications made accessible in the public portal are retained by the authors and/or other copyright owners and it is a condition of accessing publications that users recognise and abide by the legal requirements associated with these rights.

- Users may download and print one copy of any publication from the public portal for the purpose of private study or research.

- You may not further distribute the material or use it for any profit-making activity or commercial gain

- You may freely distribute the URL identifying the publication in the public portal 
BURN-OU\%, CIRCUMFERENTIAL FILM FLOW DISTRIBUTION AND

PRFCSIIRE DROP FOR AN FCCFNTRTC ANNULUS WITH IIEATED ROD

\section{Date} May 1973

A. Olsen

Abstract

12 pages +3 tables +23 illustrations

Measurements of

1. Burn-out,

2. Circumferential film flow distribution and

3. Pressure drop

in a $17 \times 27.2 \times 3500 \mathrm{~mm}$ annulus geometry are reported in this preliminary report. The eccentricity was varied between 0 and $3 \mathrm{~mm}$. The pressure and rod heat flux were held constan at 70 bar and $100.7 \mathrm{~W} / \mathrm{cm}^{2}$. Burn-out curves are presented for mass velocities between 200 and $1500 \mathrm{~kg} / \mathrm{m}^{2} \mathrm{~s}$ and for inlet subcoolings of $10{ }^{\circ} \mathrm{C}$ and $100{ }^{\circ} \mathrm{C}$. The film flow and pres sure drop measurements correspond to the steam qualities $\mathrm{x} \pm 19 \%$ and $24 \%$ for the mass velocity $\mathrm{G}=602 \mathrm{~kg} / \mathrm{m}^{2} \mathrm{~s}$ and $\mathrm{x}=20 \%$ and $23 \%$ for $\mathrm{G}=1200 \mathrm{~kg} / \mathrm{m}^{2} \mathrm{~s}$.

The influence of the circumferential rod film flow variation on burn-out is discussed.

Copies to

Library 100

Editors 80 
CONTENTS.

page

1. Introduction.

2

2. Experimental Equipment and Procedure.................

3

3.

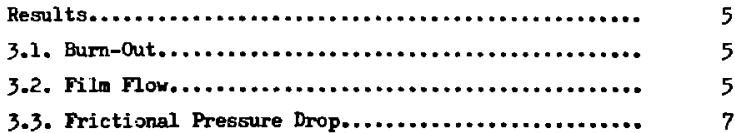

4. Conclusions.

8

5. Nomenclature

9

6. References.

10

Is: 8755002013

Tables

Figures 
The present investigation is a part of a joint project "The Scandinavian Subchannel Project" between AEC, Riso, AB Atomenergi, Sweden and IFA,Norway with the goal of developing reliable prediction methods based upon subchannel analysis for diabatic two-phase flows. One objective is to perform burn-out predictions in rod clusters by means of a "film-flow model" capable of taking into account variations in mass velocities and heat fluxes along the rods and also mutual interactions of the rods and the rods and the chroud.

The present diabatic steam-water experimental programme was primarily designed to answer some basic questions on the relationship between film flow rate and burn-out under asymmetrical conditions.

Experimental film flow measurements in eccentric annuli with airowater mixtures have been reported by Butterworth $[1]$ and schraub et al. $[2]$. Both experimenters fourd that the circumferential variation in the rod film flow rate was very amall. 
The experiments were carried out in the $0.8 \mathrm{~m}$ loop of the Laborators of Reactor Technology at KTH in Stockholm. For a detailed description of this loop see ref. $[3]$.

The annular test section consists of a directly heated 17 stainless steel rod mounted inside a $27.2 \mathrm{~m} \mathrm{i}$.d. unheated stainless steel tube. The heated length of the rod is $3500 \mathrm{~m}$. The rod can be wounted in positions corresponding to the eccentricities, $\mathrm{B}=0,0.75,1.5,2.5$ and $3.0 \mathrm{D}$. The outer tube is provided vith holes for spacers, axial pressure drop distribution measurements and needle contact probes (for the measurements of the axial film thicknesses; these measurements are not reported herein).

The rod film may be sucked off through suction holes beginning $10 \mathrm{~m}$ above the end of the heated length. The tube film is sucked off through suction boles at the same level. During three experimental periods (period 3, 4 and 5) the geometry of the perforated areas were as indicates in table 1.

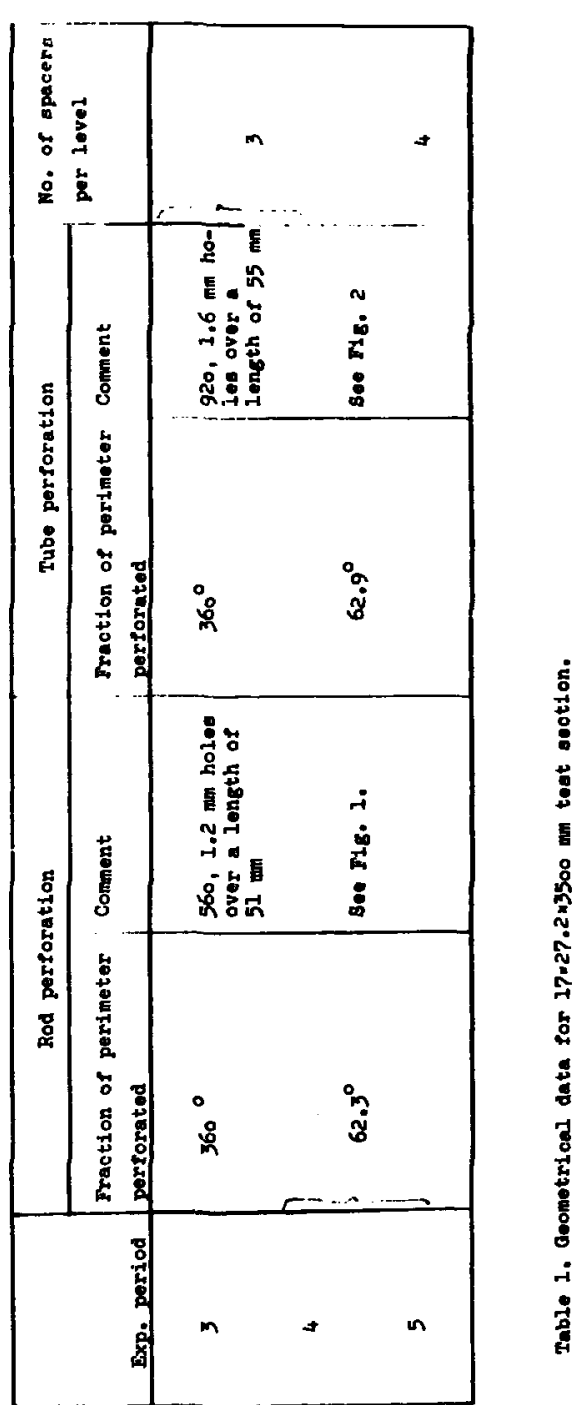


The steam-water mixtures extracted through rod and tube perforationswere condensed in separate heat exchangers and metered by venturis or orifices. The relative amounts of steam and water were determined by heat balances. Rod and tube suctions were not performed simultanously.

The relative positions of the rod and tube perforations, wich have been realized experimentally, are sumerized in the sketch Fig. 3. Note that only in "position 2.5" for concentric annulus the two perforations are not "facing" each other.

The spacers were $?$ mm dia. pins with semi-spherical tips mounted radially on the tube.

There were $500 \mathrm{~mm}$ between spacer levels. Tabel 1 indicates the number of pins per spacer level for the three experimental periods.

$$
\text { 3. Results. }
$$

\subsection{Burn-Out.}

Fig. 4 summarizes all the burn-out measurements on concentric and eccentric annulus. The graph gives the total burn-outer power $Q_{B O}$ as a function of the mass velocity $G$ for the subcoolings $\Delta t_{\text {sub }}=10{ }^{\circ} \mathrm{C}$ and $\Delta t_{\text {sub }}=100^{\circ} \mathrm{G}$. For each subcooling the eccentricity, $\mathrm{E}$ is a parameter. It is clear that burn-out is adversly affected by eccentricity for G> $500 \mathrm{~kg} / \mathrm{m}^{2} \mathrm{~s}$. For smaller mass velocities the effect may be reversed (at least for the larger subcooling). The burn-out measurements were performed during experimental period no. 5 .

\subsection{Film Flont}

In general a two-phase mixture is being sucked out through the perforation in tube and rod. Plotting the sucked out water flow rate, $\dot{m}_{w}$ versus the steam ilow rate, $\dot{\mathrm{m}}_{5}$, one obtains a "suction curve". Examples are shown in Figs. 5 and 6 for rod and tube respectively. The shape of the suction curves reflects the steam content in the film, the waviness of the film surface and the water content in the core. For the present purpose the "film flow rate", $\dot{m}_{f}$, is defined by a straight line extrapolation to $\dot{m}_{t}=0$ (The cotted lines in Figs. 5 and 6 are examples of the method of extrapolation). Fig. 7 presents suction curves for rod obtained for concentric annulus ( $E=0$ ) under various experimental conditions. We note that there is very good agreement batween experiments with a $62.3^{\circ}$ perforation. In particular : 1) Fin geometry is of no significance (compere results for experimental periods 4 and 5), 2) Tuming the perforation by $90^{\circ}$ (pos. 2.5) does not alter the results. This is taken to indicate that the film is evenly distributed around the rod for concentric conditions.

However, comparing suction results from a fraction of the perimeter (i. e. $62.3^{\circ}$ ) with results from suction from the total parimeter one notes a marked difference. The film now rate deduced from "total suction" is unexplainally lower (by $20 \%$ ) than that from "partial suction". It might be speculeted that water deposited on the fins accounts for the difference. How ever, the two sets of fins (one $0.5 \mathrm{mw}$ in height the other $1.0 \mathrm{man}$ ) gave identical results. Fig. 8 similarly displays tube suction curves for concentric annulus for three cases of "partial" suction $\left(62.9^{\circ}\right)$ and one case of suction from the total perimeter. Good agreement is found between all the results.

The experimental data for rod film how are summarized in table 2 . Figs. 9 through 12 display the angular (cireumferential) distribution of rod film flow. The results are presented as the film flows corresponding to suction from $62.3^{\circ}$ of the perimeter versus "position" i. e. the angular position of the rod (refer to the sketch, Fig. 3). The eccentricity, E, is parameter in all the graphs.

It is obvious that eccentricity has a very pronounced effect on the circumferential distribution of the rod film flow: The greater the eccentricity the more uneven the film flow rate. The maximum film flow rate occurs at the maximum gap width (position 1 ). For the higheat eccentricity ( $E=3 \mathrm{~mm}$ ) the minimum film flow rate (occuring at the minimum gap, position 4) is very close to zero.

The total rod film flow rates, $\dot{\mu}_{f}$, have been computed by assuming film flow symmetry around the geometrical line of symmetry. The results are summarized in table 3. In Figs. 13 and 14 these results are displayed as a function of the steam quality $x$ for $G=602$ and $1200 \mathrm{~kg} / \mathrm{m}^{2} \mathrm{~B}$ respectively. Also shom in these graphsare the burn-out qualities for $q^{\prime \prime}=100.7 \mathrm{w} / \mathrm{cm}^{2}$ obtained by linear interpolation in plots of measured values of $x_{B O}$ verous $q_{B O}^{\prime}$. Since for long heated lengths $x_{B O}$ versus $q_{B O}$ is almost independent of the heated length then the burn-out qualities thus obtained are roalistic estimates of the actual burn-out qualities at the two relevant mass velocities and $\mathrm{q}^{\prime \prime}=100.1 \mathrm{w} / \mathrm{cm}^{2}$. $\mathrm{Figs} .13$ and 14 may therefore be interpreted as displaying the decrease of the relative total rod film now rate as one moves vertically upward a long heated rod. The approximate $45^{\circ}$ Blopes of the lines connecting the experimental points indicate that evaporation controls film depletion. 
Examining Fig. 13 for $\mathrm{G}=1200 \mathrm{~kg} / \mathrm{m}^{2} \mathrm{~s}$ it seems clear that total film flow rate controls burn-out: burn-out occurs when the total film flow rate becomes zero. The lower burn-out qualities observed for the eccentric geometries must then be explained by the corresponding lower total film flows rather than by the uneven distribution of the film around the rod perimeter.

This conclusion is not intirely contradietel by Fig. 14 for

$G=602 \mathrm{~kg} / \mathrm{m}^{2} \mathrm{~s}$ although the picture here is less clear.

The experimental data for tube film flow are summarized in table 4. Figs. 15 through 18 show the angular distribution of tube filw flow. The effect of eccentricity is almost as pronounced as for the rod film and the lowest film flow rate is also here found in the narrow gap (pos. 4). The total tube film flow rate is not very dependent upon eccentricity. This is in contrast to what was found for the rod film flow rate for $G=1200 \mathrm{~kg} / \mathrm{m}^{2} \mathrm{~s}$.

\subsection{Fricti mal Pressure Drop.}

In Figs. 19 to 23 is given the result of the diabatic pressure drop measurements at 70 bar for a constant heat flux $q^{\prime \prime}=100.7 \mathrm{~W} / \mathrm{cm}^{2}$ and two values of flow, $G=600 \mathrm{~kg} / \mathrm{m}^{2} \mathrm{~s}$ and $1200 \mathrm{~kg} / \mathrm{m}^{2} \mathrm{~s}$. The figures gre given with the eccentricity $\mathrm{E}$ as parameter.

The multiplier is determined from the total pressure drop corrected for the influence of the hydrostatic head by means of the Bankoff-Jones void formula. The single phase pressure drop as deterwined from measurements has been expressed as

$$
\left(\frac{d p}{d z}\right)_{\text {friction }}=0.40 \operatorname{Re}^{-0.25} \frac{1}{D_{H}} \frac{G^{2}}{2 \zeta_{1}}
$$

It can be seen from the figures that the influence of eccentricity is small. However, a slight decrease in the frictional pressure drop may be observed for increasing eccentricity.
4. Conclusions.

Experiments with a $17 \times 27.2 \times 3500$ mm anmulus geometry with beated rod have led to the following preliminary conclusi ons:

1. Rod eccentricity has a pronounced adverse effect on burn-out at mass velocities greater than $500 \mathrm{~kg} / \mathrm{m}^{2} \mathrm{~s}$. At saller mass velocities eccentricity may have a small beneficial effect at swall subcoolings.

2. The circumferential variation of the rod and tube film flow rate becomes increasingly pronounced for incroasing eccentricity. The film flow rate is smallest in the narrow gap. The rod film flow becomes close to zero at the highest eccentricity $(3 \mathrm{~mm})$ even at steam qualities rather far removed from the burn-out quality.

3. The total rod film flow rate decreases with increasing eccentricity for $G=1200 \mathrm{~kg} / \mathrm{m}^{2} \mathrm{~s}$, but remains relatively unaffected at $G=602 \mathrm{~kg} / \mathrm{m}^{2} \mathrm{G}$.

4. Burn-out performance seemb primarily to be controlied by the total rod film flow rate.

5. Eccentricity has possibly a small (beneficial) effect on the preesure drop. 


\section{Nomenclature.}

hydraulic diameter

eccentricity

mass velocity

total film flow rate

filn flow rate ("partial suction")

steam flow rate("partial suction")

water flow rate ("partial suction")

\section{pressure}

total power

specific power

q" "

$\mathrm{Re}=\mathrm{GD}_{\mathrm{H}} / \mu$

$x_{0}$

$\Delta \mathrm{t}$

$t_{\text {sub }}$

$9_{1}$

$\mu$
Rejnolds number

steam quality

steam quality at outlet

axial coordinate

inlet subcooling

density of liquid

two-phase multiplies

dymanic viscosity

\section{References.}

1. Butterworth, D. : Air-water climbing film flow in an eccentric annuius. U. K. A. E. A., Report No. AKRe-R5787 (Hay 1968).

2. Schraub, F. A. et al.: GEAP-5739 (1969).

3. Jensen, A., O1sen, A., Mannov, G., Seir Olsen. J., Hartig, A. Rise-M-1384. 
Evesure: $F=7380$

\begin{tabular}{|c|c|c|c|c|c|c|}
\hline $\begin{array}{l}\mathrm{q}_{\text {roc }}^{n} \\
\text { w/cm }\end{array}$ & $\begin{array}{c}G \\
\mathrm{~kg} / \mathrm{m}^{2} \mathrm{~s}\end{array}$ & $\begin{array}{l}x_{0} \\
s \quad g\end{array}$ & Pos. 1 & Pos. 2.5 & & $\begin{array}{c}E \\
\mathrm{~mm}\end{array}$ \\
\hline 100.7 & 602 & 23.9 & $(3.6) \quad 3.6$ & 3.6 & $2.9 \vdots$ & 0 \\
\hline 100.7 & 602 & 19.0 & $(5.2)$ & & $\{3.6]$ & 0 \\
\hline 100.8 & 1200 & 23.2 & $(5.6) 5.8$ & 5.0 & & 0 \\
\hline 100.7 & 1201 & 20.2 & $(7.4)$ & & {$[5.2]$} & 0 \\
\hline
\end{tabular}

\begin{tabular}{|c|c|c|c|c|c|c|c|c|c|c|c|}
\hline$\left\{\begin{array}{l}\mathrm{Mrod} \\
\omega / \mathrm{cm}^{2}\end{array}\right.$ & $\begin{array}{c}\mathrm{G} \\
\mathrm{kg} / \mathrm{m}^{2} \mathrm{~s}\end{array}$ & $\begin{array}{l}x_{0} \\
z\end{array}$ & \multicolumn{2}{|c|}{ Pos. 1} & \multicolumn{2}{|c|}{ Pos. 2} & \multicolumn{2}{|c|}{ Pos. 3} & \multicolumn{2}{|c|}{ Pos. 4} & $\begin{array}{c}E \\
\mathrm{~mm}\end{array}$ \\
\hline \multirow{3}{*}{100.7} & \multirow{3}{*}{602} & \multirow{3}{*}{23.9} & $(5.6)$ & 5.7 & $(3.7)$ & 4.8 & $(2.6)$ & 3.7 & $(2.1)$ & 3.0 & 1.5 \\
\hline & & & 1 & 6.3 & & 4.5 & & 2.5 & & 1.8 & 2.5 \\
\hline & & & $(6.5)$ & & $(5.0)$ & & $(1.5)$ & & $(0.4)$ & & 3.0 \\
\hline \multirow{2}{*}{100.7} & \multirow{2}{*}{602} & \multirow{2}{*}{19.0} & $(7.7) !$ & & $(4.7)$ & & $(2.0)$ & & $(2.0)$ & & 1.5 \\
\hline & & & $(9.2)$ & & $(5.3)$ & 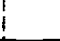 & $(1.0)$ & & $(1.0)$ & & 3.0 \\
\hline \multirow{3}{*}{100.8} & \multirow{3}{*}{1200} & \multirow{3}{*}{23.2} & & 6.6 & & 5.2 & & 4.3 & & 3.5 & 1.5 \\
\hline & & & & 4.5 & & 3.8 & & 3.2 & & 2.5 & 2.5 \\
\hline & & & & & & & $(3.0)$ & & & & 3.0 \\
\hline \multirow{2}{*}{100.7} & \multirow{2}{*}{1201} & \multirow{2}{*}{20.2} & $(5.8)$ & & $(6.5)$ & & $(4.3)$ & & $(3.6)$ & & 1.5 \\
\hline & & & $(9.2) !$ & & $(7.9)$ & & $(2.4)$ & & $(-)$ & & 3.0 \\
\hline
\end{tabular}

Numbers in [] brackets: Exp. period No. 3.

Numbers in () brackets: Exp. period No. 4.

Numbers without brackets: Exp. period No. 5 .

(Exp. period No, 3 corresponds to suction from the total perimeter. For fin configurations corresponding to Exp. periods No. 4 and 5 see fig. 1 ).

Table 2 : Rod film flow rates on $62.3^{\circ}$ in $\mathrm{g} / \mathrm{s}$.

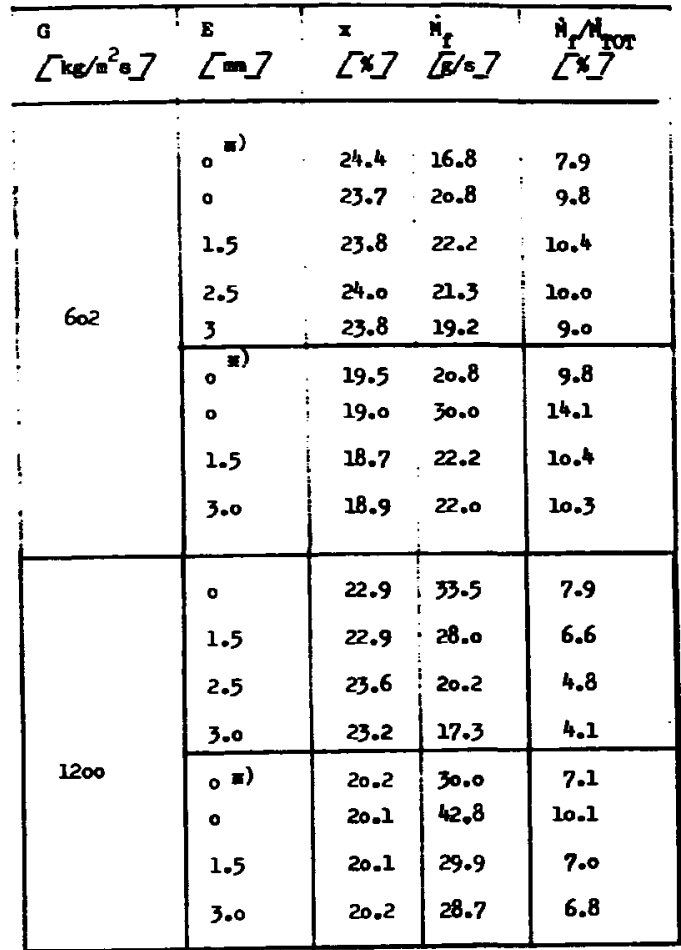

Table 3. Total rod fil now rates.

-) Suction $\operatorname{srom} 360^{\circ}$. 


\begin{tabular}{|c|c|c|c|c|c|c|c|}
\hline $\begin{array}{l}q_{r o t}^{n} \\
w / \mathrm{cm}^{2}\end{array}$ & $\begin{array}{c}\mathrm{kg} / \mathrm{m}^{2} \mathrm{~s} \\
\end{array}$ & $\begin{array}{l}x_{0} \\
z_{0}\end{array}$ & Pos. & - 1 & Pos. 2.5 & & $\begin{array}{r}\mathrm{E} \\
\mathrm{mm}\end{array}$ \\
\hline 100.7 & 602 & 23.7 & $(20.5)$ & 21.4 & 19.0 & {$[20.0]$} & 0 \\
\hline 100.7 & 603 & 18.9 & $(20.6)$ & & & $20.6)$ & 0 \\
\hline 100.9 & 1201 & 23.1 & & 31.0 & 31.0 & & 0 \\
\hline 100.6 & 1201 & 20.1 & $(27.8)$ & & & $\{28.5\}$ & 0 \\
\hline
\end{tabular}

\begin{tabular}{|c|c|c|c|c|c|c|c|c|c|c|c|}
\hline$q^{\prime \prime} \operatorname{rod}^{2}$ & $\begin{array}{c}\mathrm{G} \\
\mathrm{kg}: \mathrm{m}^{2} \mathrm{~s}\end{array}$ & $\begin{array}{l}x_{0} \\
f\end{array}$ & Pos & - 1 & Pos & . 2 & Pos & - 3 & Pos. & . 4 & $\begin{array}{c}E \\
\mathrm{~mm}\end{array}$ \\
\hline \multirow{3}{*}{100.7} & \multirow{3}{*}{602} & \multirow{3}{*}{23.7} & $(24.0)$ & 33.0 & $(24.0)$ & 24.3 & $(16.4)$ & 21.5 & $(13.5)$ & 18.3 & 1.5 \\
\hline & & & & 31.2 & & 26.0 & & 16.1 & & 9.6 & 2.5 \\
\hline & & & $(29.0)$ & & $(26.4)$ & & $(15.5)$ & & $(9.0)$ & & 3.0 \\
\hline \multirow{2}{*}{100.7} & \multirow{2}{*}{603} & \multirow{2}{*}{18.9} & $(23.5)$ & & $(22.1)$ & & $(16.1)$ & & $(13.0)$ & & 1.5 \\
\hline & & & $(31.0) i$ & & $(25.0)$ & & $(16.5)$ & & $(7.0)$ & & 3.0 \\
\hline \multirow{3}{*}{100.9} & \multirow{3}{*}{1201} & \multirow{3}{*}{23.1} & & 35.0 & & 36.5 & & 33.0 & & 27.0 & 1.5 \\
\hline & & & & 35.4 & & 36.4 & & 24.8 & & 17.3 & 2.5 \\
\hline & & & & & & & $(25.2)$ & & & & 3.0 \\
\hline \multirow{2}{*}{300.6} & \multirow{2}{*}{1201} & \multirow{2}{*}{20.1} & $(39.4)$ & & $(35.0)$ & & $(29.0)$ & & $(24,3)$ & & 1.5 \\
\hline & & & $(35.5)$ & & $(35.5)$ & & $(23.5)$ & & $(8.0)$ & & 3.0 \\
\hline
\end{tabular}

Numbers in [ ] brackets: Exp. period No. 3 .

Numbers in () brackets: Exp. Period No. 4.

Numbers without brackets: Exp. period No. 5 .

Exp. period No. 3 currespuncis to suction from the total perimeter. For $f$ in configurations corresponding to Exp. periods No. 4 and 5 see fig. 2).

Table 4: Tube film flow rates on $6.2 .9^{\circ}$ in $\mathrm{g} / \mathrm{s}$.
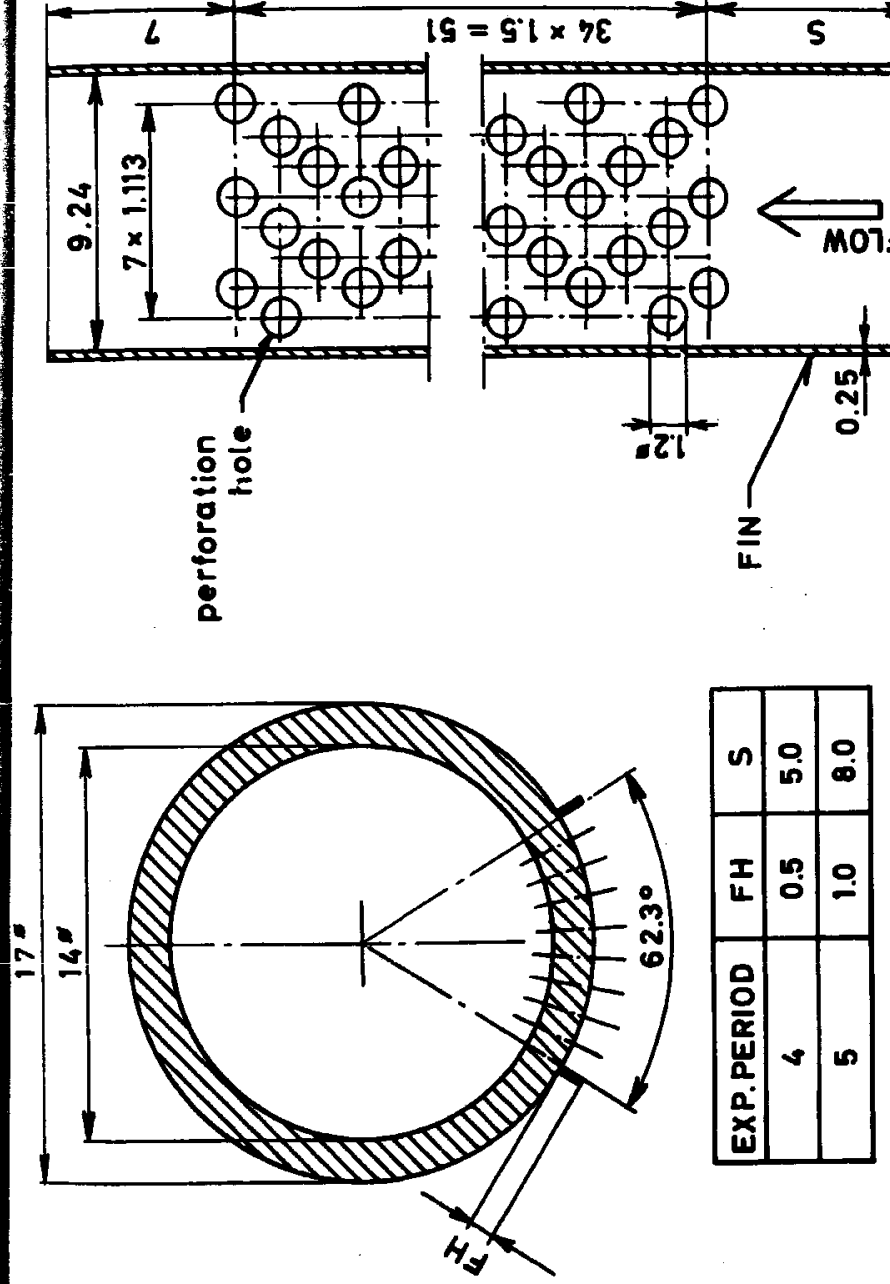

등ํํㅇ

는

8
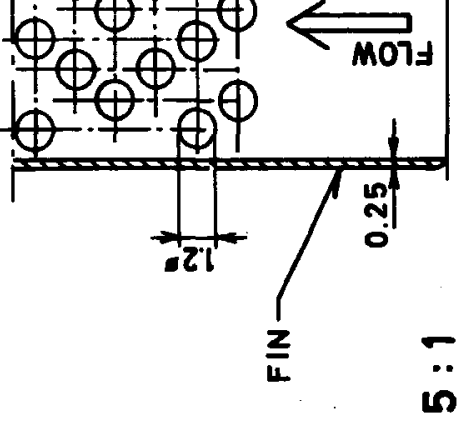

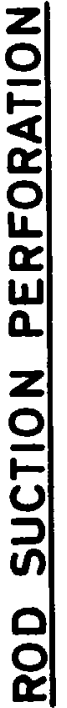



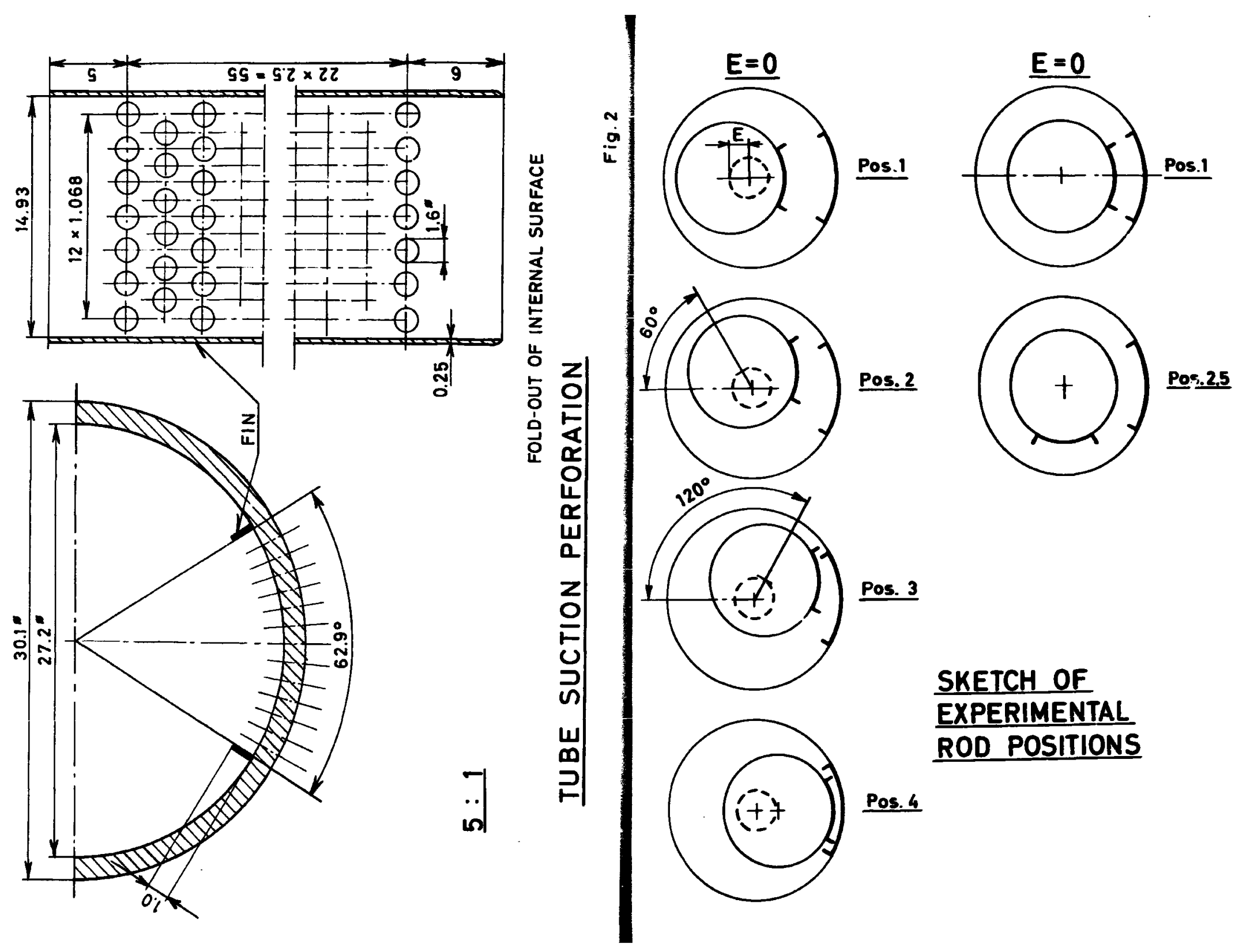

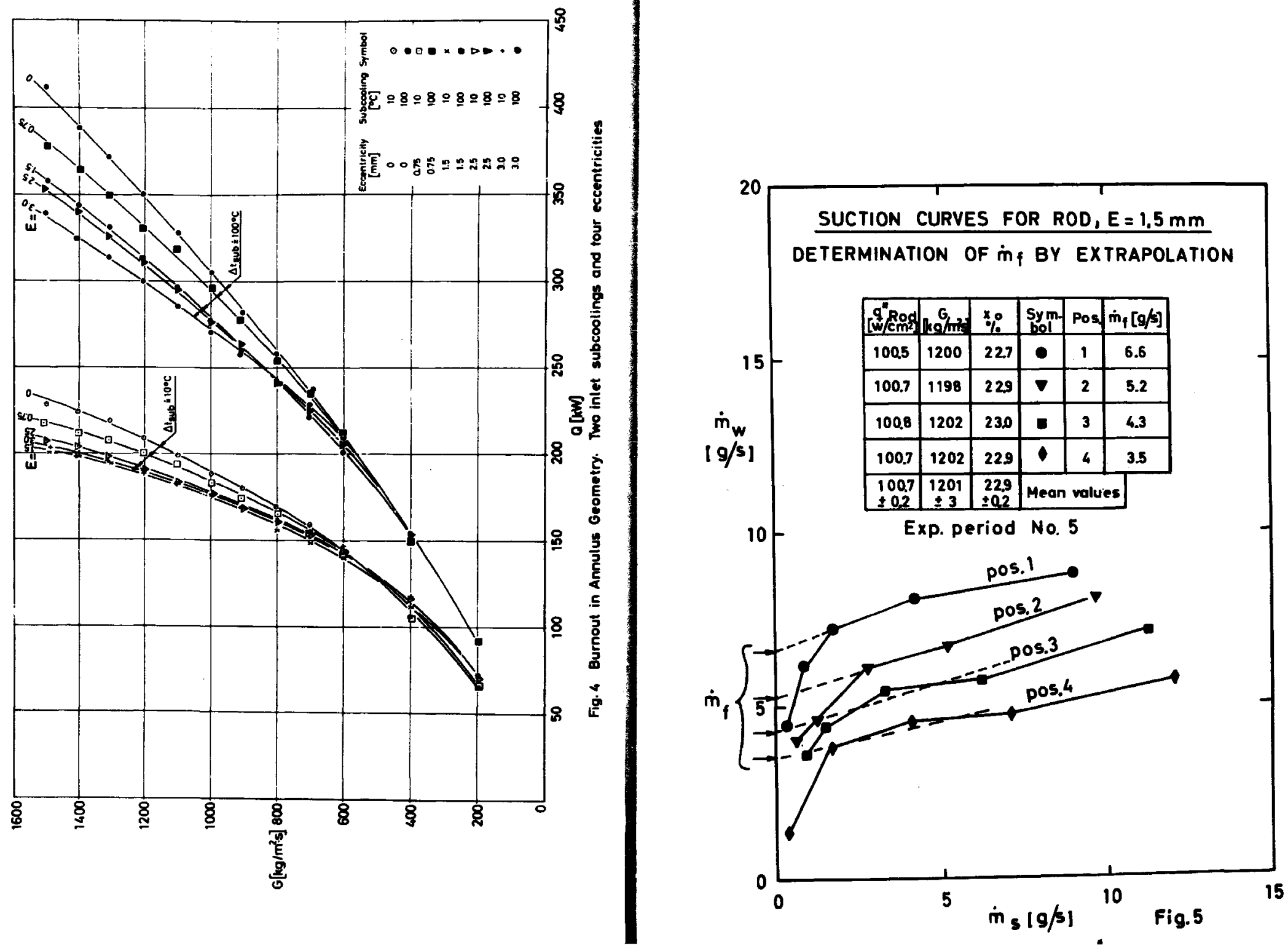

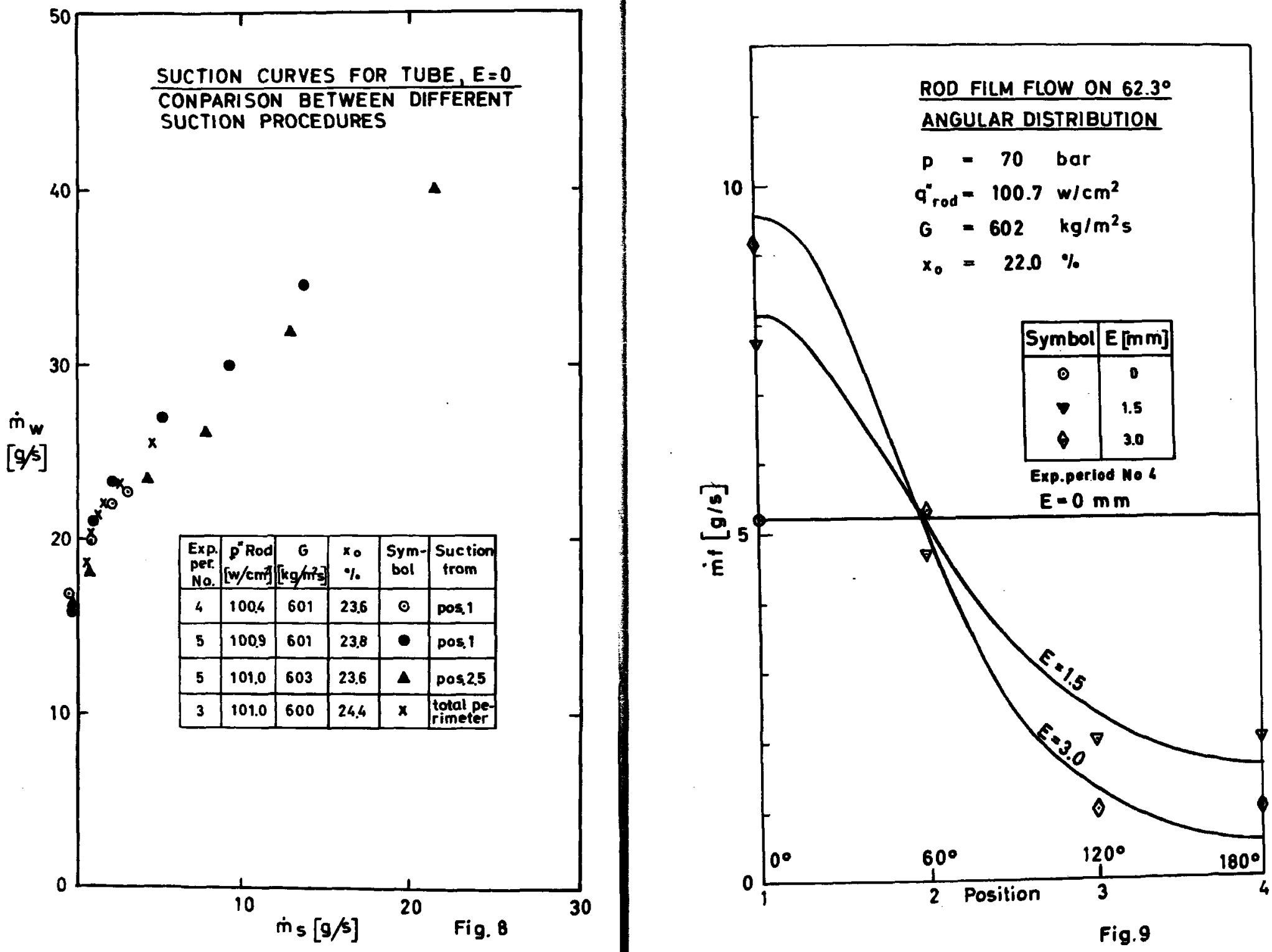

Fig. 9 

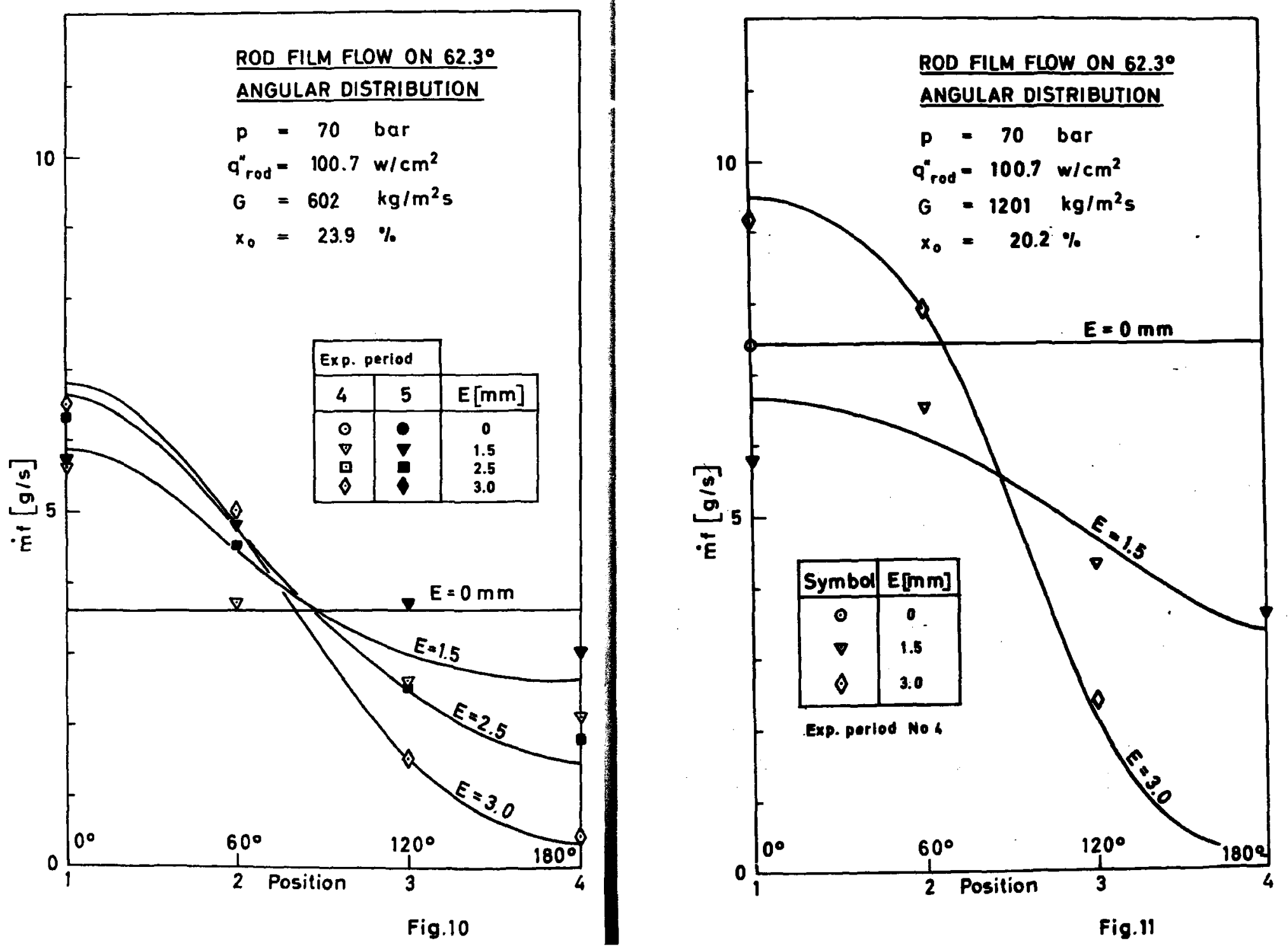

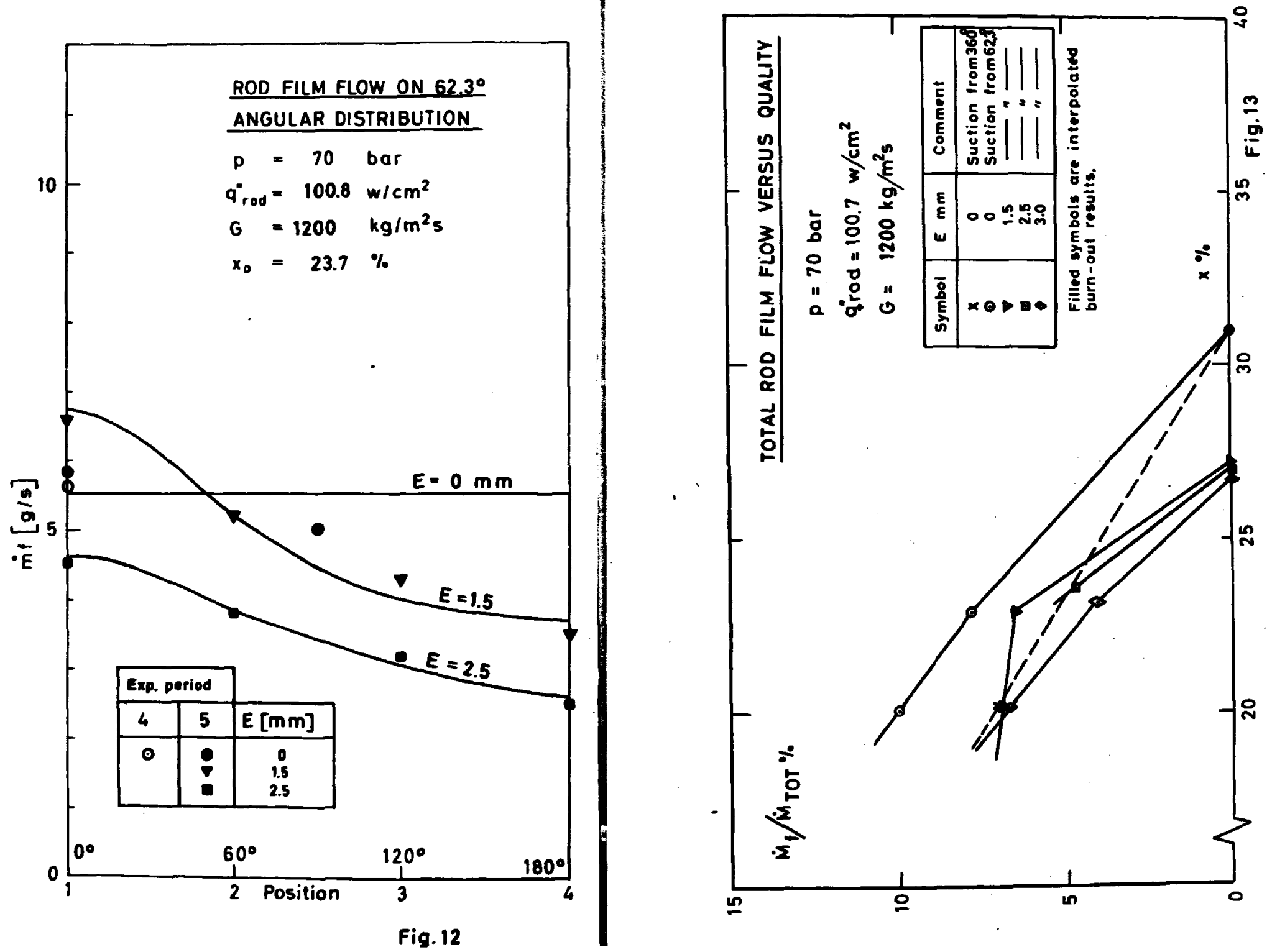


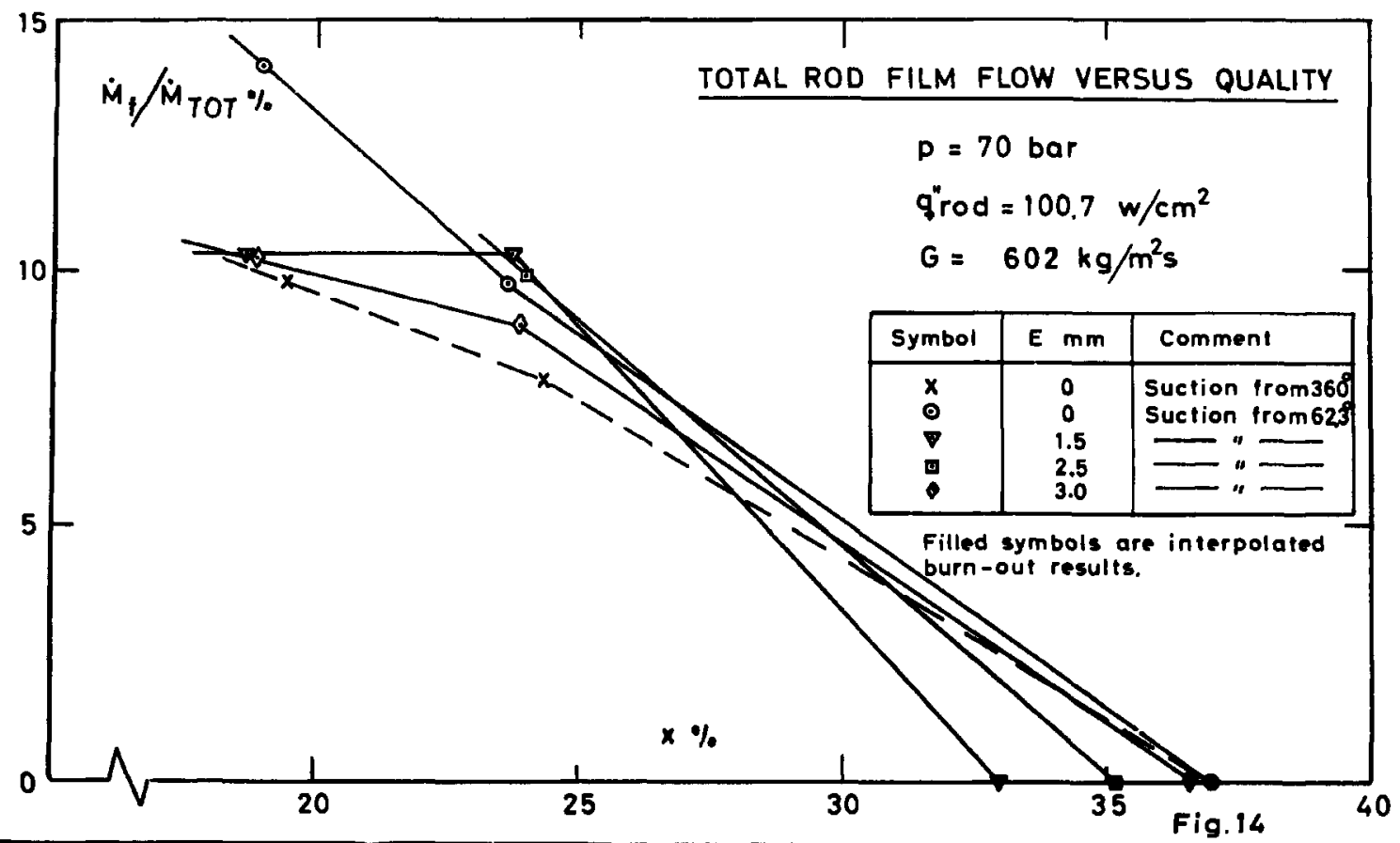

s.

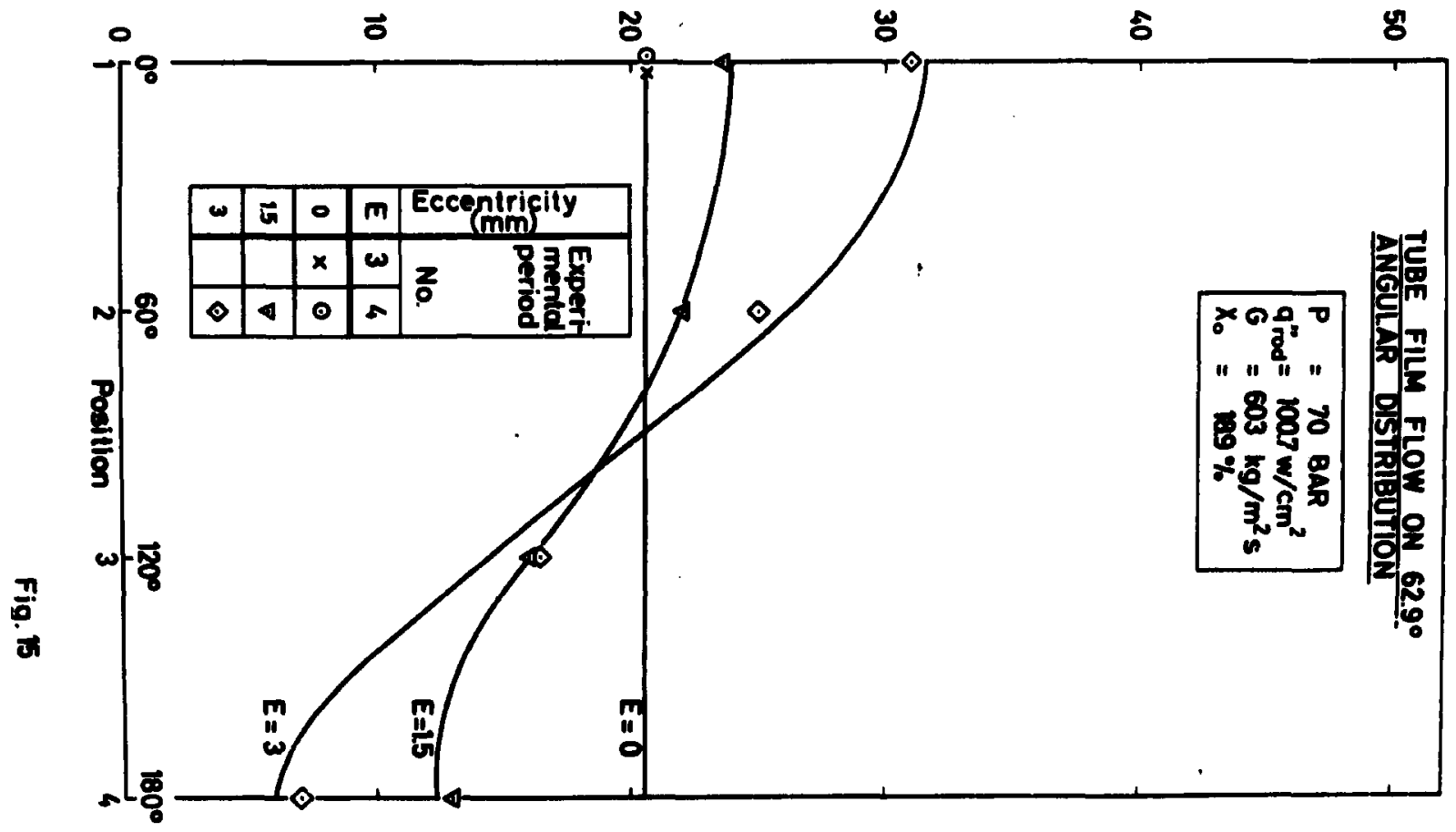




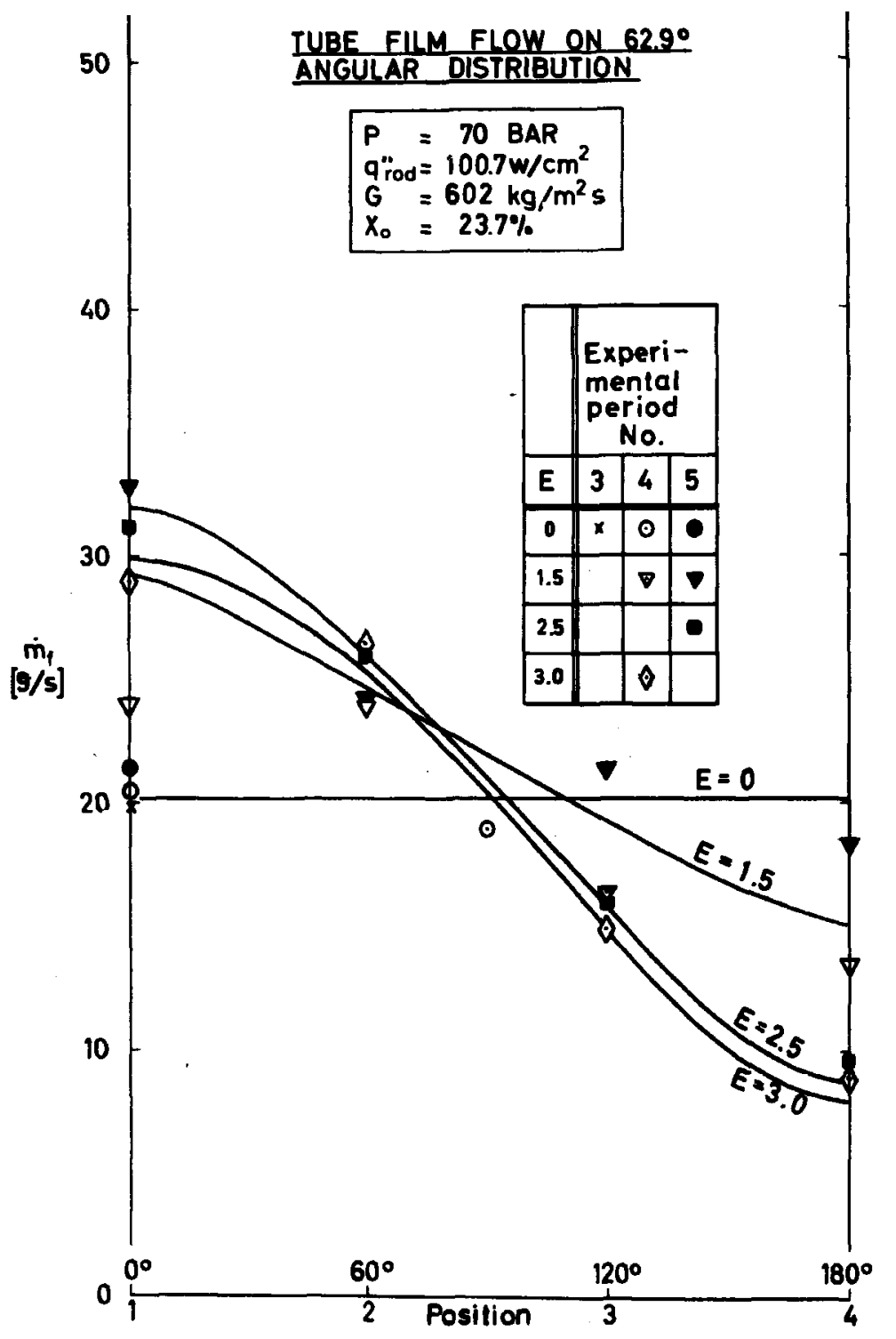

Fig. 16

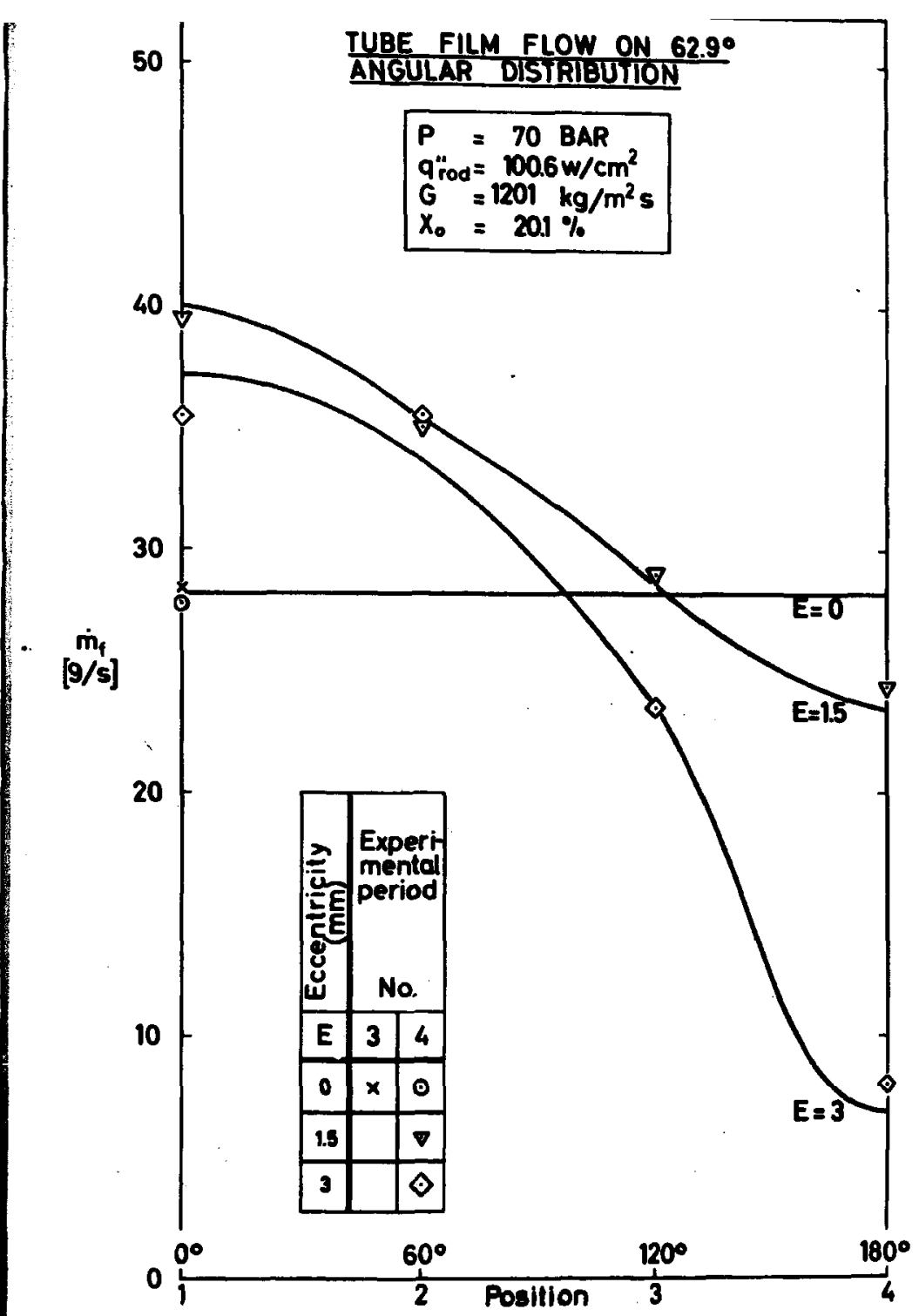

Fig. 17 


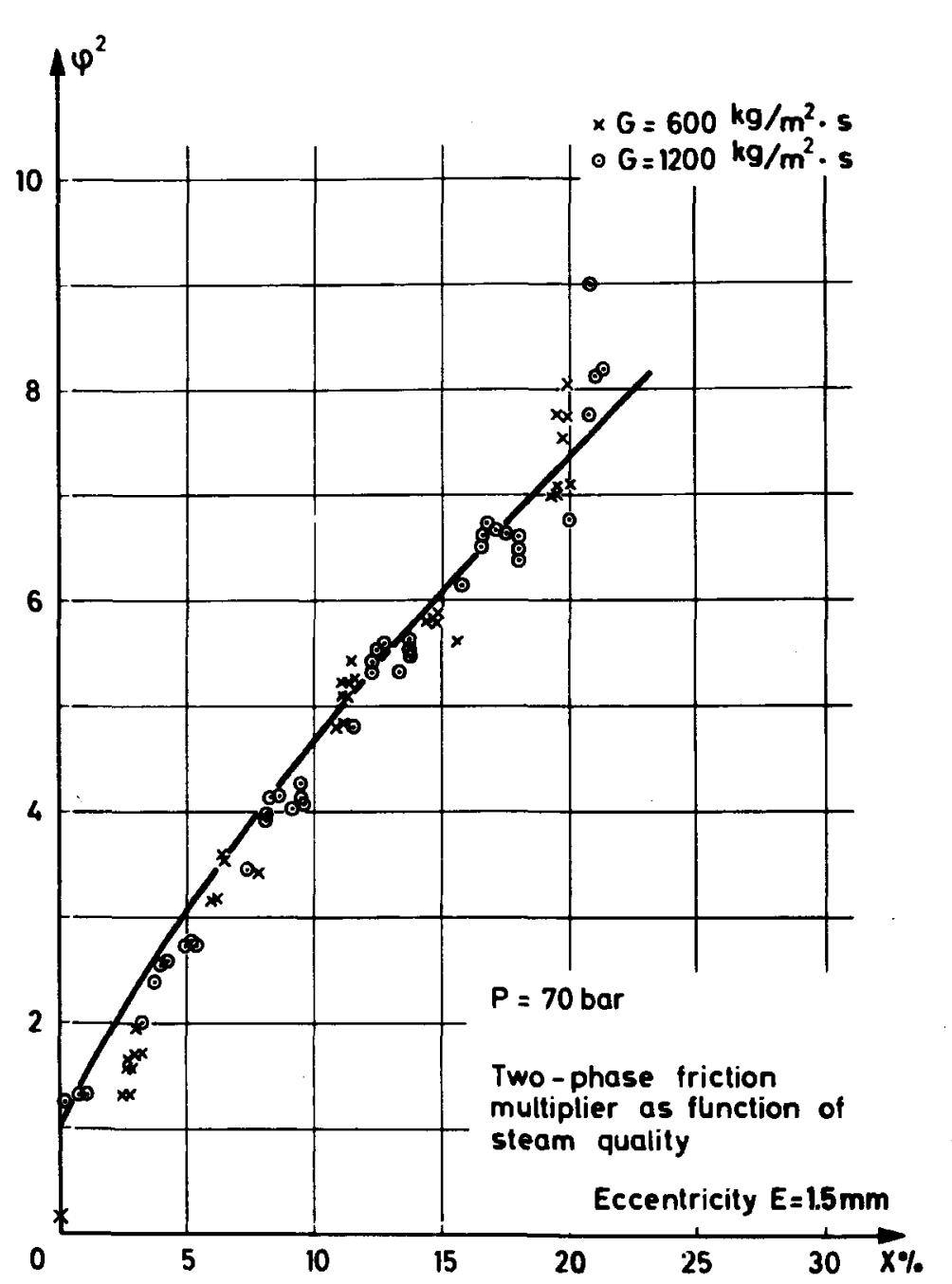

Fig. 20

Fig. 21 

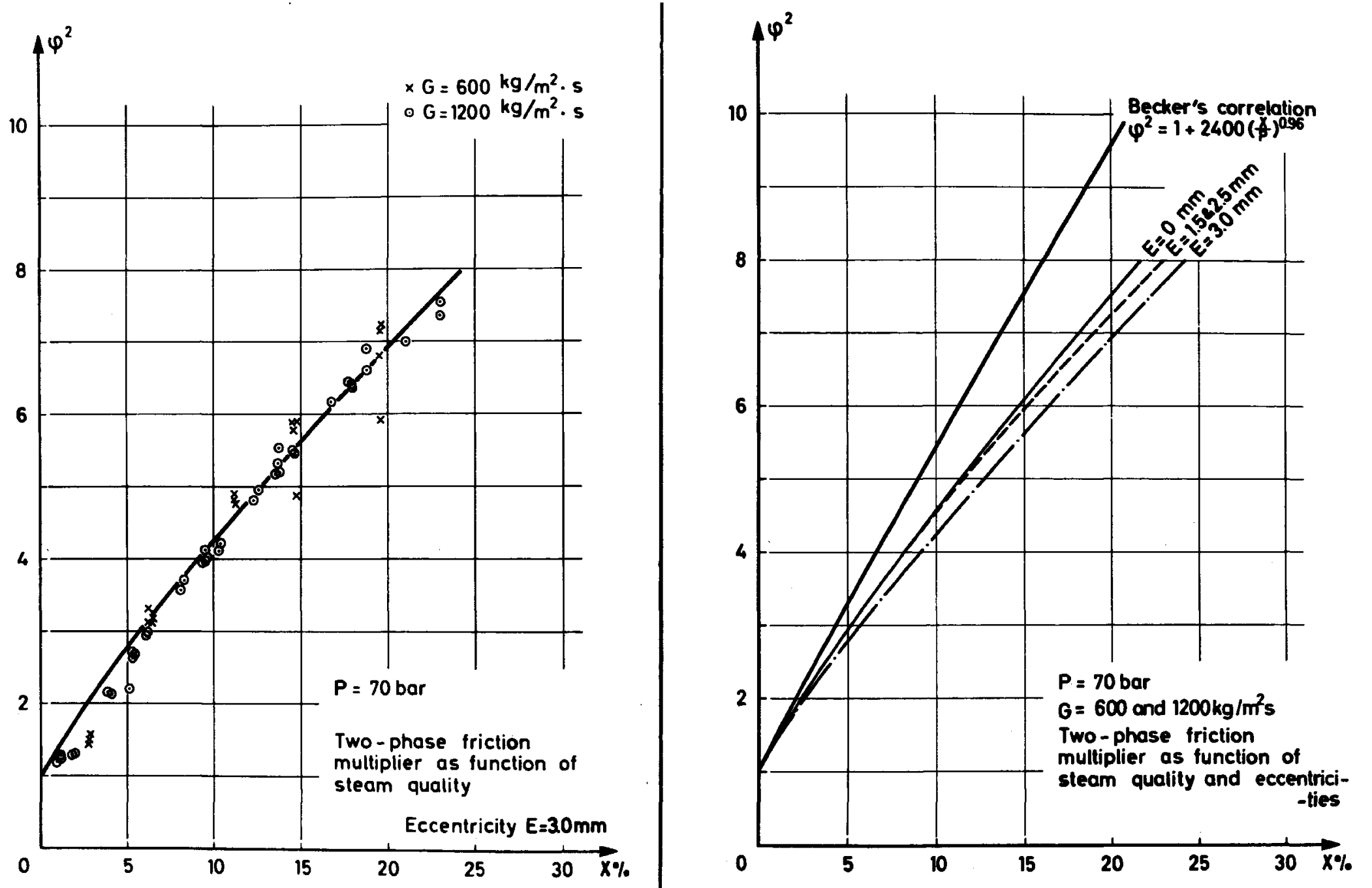

Fig. 22

Fig. 23 